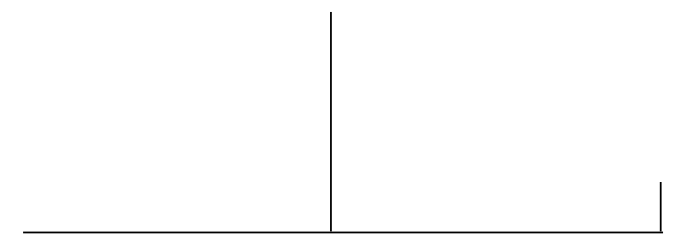

Rev. Latinoam. Psicopat. Fund., São Paulo, v. 15, n. 2, p. 235-239, junho 2012

\title{
Editorial
}

\section{Método clínico, ciência e subjetividade}

Ana Maria Rudge

Muito alegre e honrada com o convite do editor da Revista Latinoamericana de Psicopatologia Fundamental, meu amigo Manoel Berlinck, para escrever o editorial deste número, não apenas pela excelência da revista, mas pelo vínculo de longa data com a Associação Universitária de Pesquisa em Psicopatologia Fundamental, sociedade científica internacional da qual sou membro fundador, deparei-me com a dúvida de qual das vertentes de meu interesse e das experiências nesse rico intercâmbio no seio da Associação poderia privilegiar. São inúmeras as possibilidades, falar de pesquisas que vêm sendo desenvolvidas, dos congressos em que a experiência clínica de colegas traz novas perspectivas e vem a enriquecer nossa escuta, de associações de trabalho que se produzem a partir desses encontros entre pesquisadores de diferentes universidades, estados e países, e que resultam em produções conjuntas, organização de livros, redação de artigos conjuntos etc.

A Associação da qual a Revista é o órgão oficial tem mostrado enorme vitalidade na reunião de pesquisadores de diferentes pontos de vista e filiações institucionais. A política editorial da Revista, que aceita artigos de diferentes posições teóricas e mesmo de autores que atuam em diferentes campos de saber, não se fechando em dogmatismos quando se trata da abordagem das patologias da alma, não significa a ausência de um projeto muito claro e bem definido, que vem se concretizando ao longo desses anos. $\mathrm{O}$ que têm em comum é o objeto, o pathos psíquico, e a clínica, que leva em conta o sujeito, fugindo da tendência atual à objetificação que leva à infla- 
ção do valor de sistemas classificatórios e protocolos de tratamento, tendência que é tributária de uma ideologia, o cientificismo, que se instaurou na modernidade.

No estudo da psicopatologia, como discurso (logos) da paixão, do afeto (pathos) psíquico, a reflexão sobre o método clínico como fundamento da psicopatologia se impõe (Berlinck, 2009). No momento, esse tema merece uma pesquisa em andamento, pesquisa "guarda-chuva" com o apoio do CNPq, contando com a participação de vários membros da AUPPF, coordenada por Manoel Berlinck, Mário Eduardo Costa Pereira e Ana Maria Rudge: "O método clínico: projeto de pesquisa temático".

O método clínico designa o esforço de diagnóstico e tratamento de um determinado sujeito, seja o profissional um médico, um psiquiatra, um psicólogo ou um psicanalista, mas nem sempre esse método tem reconhecida sua especificidade epistemológica. Geralmente sua legitimidade é defendida com base na ideia de que ele seria a aplicação do método científico na prática diagnóstica e terapêutica, o que redunda em atrelar sua dignidade à que se confere à ciência. Um exemplo disso é o que se verifica nas tentativas atuais de atrelar a psicanálise às neurociências.

Entretanto essa formulação é bastante simplificadora, e a heterogeneidade entre a ciência e o método clínico vigora em qualquer campo da clínica. Como observa Serpa (2003), Canguilhem (1966) reconhece que a medicina é "uma técnica ou uma arte situada na confluência de várias ciências, mais do que uma ciência propriamente dita" (p. 16). Embora mantenha laços com a ciência, seu compromisso fundamental é com a clínica e a terapêutica, e por esta razão ela não pode ser "inteiramente reduzida ao simples conhecimento" (ibid.).

O mesmo ocorre com a "medicina da alma", e Freud foi bastante claro quanto a isso. Aos que criticavam a psicanálise por não ser uma ciência, e que solicitavam comprovações de sua eficácia, rebate afirmando que "a psicanálise não é uma investigação científica imparcial, mas uma medida terapêutica. Sua essência não é provar nada, nas meramente alterar algo" (Freud, 1909, p. 104).

Assim, Freud se recusa a cair na esparrela de fazer a má escolha nesse dilema em que a orientação quantitativa e antiantropocêntrica das ciências da natureza, a partir de Galileu, colocou às ciências humanas: "ou assumir um estatuto científico frágil para chegar a resultados relevantes, ou assumir um estatuto científico forte para chegar a resultados de pouca relevância" (Ginzburg, 1989, p. 178). A segunda opção, que foi a predominantemente tomada pela Psicologia do ego, de uma espécie de imitação da metodologia das ciências da natureza, teve os pífios resultados que se sabe.

$\mathrm{Na}$ psicanálise, pesquisa e tratamento coincidem (Freud, 1912, p. 114). Falamos de uma teoria psicanalítica, mas trata-se de uma teoria que desfruta de uma posição sui generis, muito diversa das teorias da ciência dura. Não apenas 


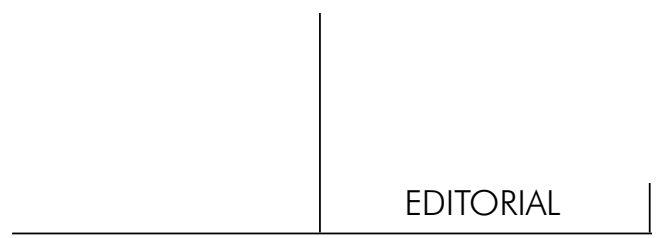

Freud defende a vocação da teoria psicanalítica para manter-se sempre inacabada, como recomenda que seja posta em suspensão quando o atendimento se inicia, porque é o inédito de cada processo que se impõe. Que status conceder à teoria neste âmbito?

Platão definiu o saber por critérios de racionalidade e pela exigência de coerência, de tal forma que, mesmo tendo sua filosofia se desenvolvido tão antes do advento da ciência experimental, pode-se considerar sua obra como estando no horizonte de toda a investigação teórica, até nossos dias (Châtelet, 1994, p. 65).

Apesar desse esforço de construir uma "epistemé", Platão percebe que ela não dá conta de tudo. No diálogo, Mênon, que versa sobre a virtude, revela que a epistemé, o saber ligado em uma articulação formal, não cobre o campo da experiência humana. Não há uma epistemé da virtude, e a ciência não pode ensinar os caminhos para se chegar a ela.

Platão proporá uma distinção entre a epistemé, saber teórico, e ortodoxa, a opinião justa. Ora, a virtude não se ensina e portanto não é ciência, como também não é um dom da natureza. Não é só o conhecimento que conduz à ação bem-sucedida, esta é a chave do texto. Um exemplo que esclarece este ponto de vista é enunciado por Platão: para ir a Larissa, pode nos conduzir bem um guia que conheça o caminho, ou um guia que, embora sem o conhecer, com base em uma conjetura, nos leve corretamente. A ortodoxa, opinião justa, não depende de conhecimento prévio. Esse diálogo será citado em inúmeras ocasiões por Lacan. No Seminário 2 (1987) cita-o para articular a distinção entre epistemé e ortodoxa à antinomia entre saber e verdade, tal como propõe a partir do campo da psicanálise.

O campo da prática analítica é anterior à constituição do saber, o nível em que se dá a descoberta é o da ortodoxia, o da produção da verdade. A interpretação, portanto, não se funda em um saber, o saber na psicanálise é $a$ posteriori.

Na prática, no particular de uma situação histórica, é que tem lugar a opinião verdadeira, e portanto ela é ato, e não saber. A verdade nascente tem seu campo no diálogo, e em sua emergência, nesse domínio, não se articula em um saber generalizável. Assim, no campo da psicanálise a investigação é de ordem indutiva, ao contrário da ciência da natureza, hipotético-dedutiva e experimental desde Galileu.

Sócrates conclui que a virtude é ortodoxa, opinião verdadeira, algo que é como uma crença, uma convicção, cega mas justa (Koyré, 1969, p. 29), e que para a prática, para a ação, é equivalente ao saber, embora, diferentemente do saber, ela não seja encadeada por um raciocínio de causalidade.

A constituição do saber teórico da psicanálise ocorre a partir da experiência, do particular, mas para Lacan há uma antinomia em certa medida irredutível, entre os dois planos. Como no Mênon, é a partir da virtude que um campo é aberto ao 
saber, mas a própria virtude, no que diz respeito à forma de sua emergência e sua transmissão, fica fora do campo. Não é tudo que o saber pode recobrar retroativamente. $\mathrm{O}$ saber ao qual se articula a verdade é dotado de uma inércia própria, que lhe faz perder algo da virtude, ou seja, que leva a um esquecimento do campo particular, das ocorrências onde pôde surgir.

O que se opõe ao ato não é a fala, é a tese, diz Lacan. O ato de fala, a enunciação nas circunstâncias particulares em que ela se dá, como na transferência, que envolve uma suposição de saber de ordem amorosa no analista, é o fundamental de uma análise. O inconsciente é exatamente falar mais do que se sabe de antemão, e então se espantar com o que escuta. Concordamos assim com a interpretação de Miller (1981) quando afirma que a teoria psicanalítica era, para Lacan, não tanto uma teoria do inconsciente, mas uma teoria da estrutura da situação psicanalítica. É nela que o inconsciente se produz.

Embora a especificidade de cada um dos campos que se utiliza do método clínico não possa ser desconhecido, a fala e a escuta são fundamentais em qualquer uma delas porque há um sujeito em questão, o que significa que a psicanálise apresenta um valor inquestionável para todo o terreno da clínica. Um exemplo eloquente disso me foi relatado por um colega analista. Ouvia as associações de uma analisanda que contava, bastante angustiada, algo que há um bom tempo havia ocorrido com um de seus irmãos, que foi vítima de um enfarte em um lugar público, mas que não se dava conta da gravidade do que lhe estava ocorrendo. Uma escuta amorosa que captou aquilo que a própria analisanda lhe dizia sem saber, o analista identificou o fato de que a analisanda estava, ela mesma, à beira de um enfarte. Interrompeu a sessão encaminhando-a a tempo para um atendimento médico de emergência.

Numa época em que estão em ascensão a ideologia cientificista, os diagnósticos baseados em sistemas classificatórios que descrevem e agrupam sintomas, recorrendo de imediato à eficácia dos medicamentos para silenciá-los e aos protocolos de tratamento que se pretendem objetivos, o valor da psicanálise como prática da escuta e como instrumento para uma crítica da cultura e das posições que esvaziam a subjetividade é inquestionável.

\section{Referências}

BERLINCK, M. Editorial - O método clínico: fundamento da psicopatologia. Revista Latinoamericana de Psicopatologia Fundamental, São Paulo, V. 12, n. 3, set. 2009. Disponível em: http://dx.doi.org/10.1590/S1415-47142009000300001 


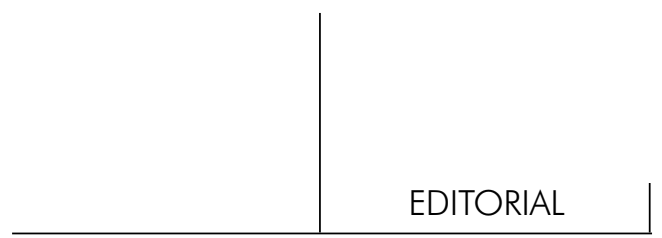

ChÂTELET, F. Uma história da razão: entrevistas com Émile Noël. Rio de Janeiro: Jorge Zahar, 1994.

Canguilhem, G. (1966). O normal e o patológico. Rio de Janeiro: Forense Universitária, 1982.

FreUd, S. (1909). Analysis of a phobia in a five-year boy. In: The Standard Edition of the Complete Psychological Works of Sigmund Freud (SE). London: The Hogart Press, 1975. V. X, p. 5-148.

. (1912). Recommendations on analytic technique. In: The Standard Edition of the Complete Psychological Works of Sigmund Freud (SE). London: The Hogart Press, 1975. V. XII, p. 109-120.

GinzBurg, C. Sinais: raízes de um paradigma indiciário. In: Mitos, emblemas, sinais Morfologia e História. São Paulo: Companhia das Letras, 1989.

KoYRÉ, A. Introduction à la lecture de Platon suivi de Entretiens sur Descartes. Paris: Gallimard, 1962.

LaCAn, J. (1954-1955). O seminário. Livro 2. O eu na teoria de Freud e na técnica da psicanálise. Rio de Janeiro: Jorge Zahar, 1987. . (1967-1968). O seminário. Livro 15. O ato psicanalítico. Inédito.

Miller, J.A. Jacques Lacan 1901-1981. Ornicar?, n. 24, p. 35-46, 9 de setembro de 1981.

Platão. Mênon, em Diálogos. Rio de Janeiro: Globo, 1966.

Rudge, A. M. O ato psicanalítico e o Ménon. Tempo Psicanalítico, Rio de Janeiro, n. 26, p. 98-113, 1992.

SERPA, O.D. Indivíduo, organismo e doença: a atualidade de $O$ normal e o patológico, de Georges Canguilhem. Psicologia Clínica (PUC/RJ) v. 15, n. 1, p. 121-135, 2003.

\section{Ana Maria Rudge}

Membro Psicanalista da Sociedade de Psicanálise Iracy Doyle (Rio de Janeiro, RJ, Br); Professora Associada do Departamento de Psicologia da Pontifícia Universidade Católica do Rio de Janeiro - PUC-Rio (Rio de Janeiro, RJ, Br); Pesquisadora do Conselho Nacional de Desenvolvimento Científico e Tecnológico - CNPq (Brasília, DF, Br); Pesquisadora e Membro Fundador da Associação Universitária de Pesquisa em Psicopatologia Fundamental (São Paulo, SP. Br) Rua Marquês de São Vicente, 225 - Edifício Cardeal Leme, sala 201 - Gávea 22453-900 Rio de Janeiro, RJ, Br e-mail: ana.rudge@uol.com.br 